\title{
Mentalization, specific attachment, and relational satisfaction from the intrapsychic and interpersonal perspectives
}

\begin{abstract}
Mentalization is a process of social cognition that involves making inferences about one's own behavior and the behavior of other people on the basis of unobservable mental states. Particularly in psychodynamic approaches, mentalization is conceptualized in the context of activation of internal representation of emotional relationship. In this study, we checked whether mentalization constitutes a predictor of relational satisfaction in the context of one's own and the partner's specific attachment. The research sample was composed of 32 heterosexual couples living together for at least two years. Three tools were applied: the Mental State Task, Experiences in Close Relationships-Relationship Structures, and the Relationship Assessment Scale. The results indicate a strong negative effect of one's own attachment anxiety and avoidance, and a strong effect of the partner's attachment anxiety on the relationship satisfaction for both men and women. In women, the incremental validity of mentalization in predicting satisfaction in the relationship beyond the attachment of their partners has been observed. The results are discussed in the context of the intrapsychic and interpersonal aspects of mentalization and attachment.
\end{abstract}

Key words: mentalization, specific attachment, relational satisfaction

\section{Introduction}

Researchers investigating romantic relationships have discovered many factors that influence their stability and the satisfaction they produce-including, for example, various personality characteristics, gender roles, and demographic factors (for an overview, see Bradbury, Fincham, \& Beach, 2000). Among the most important determinants of relational outcome are intrapsychic structures and processes formed in the past that are activated by stimuli occurring in the present relationship. The intrapsychic structures, which provide patterns of reaction in the relationship, are conceptualized as, inter alia, internal working models (Bowlby, 1973), self-object-affect dyads (Kernberg \& Caligor, 2005), or emotional schemata (Bucci, 2005), and always incorporate representations of oneself and others in the emotional relationships. The structures are closely related to processes that allow the processing of emotional and relational experience, such as mentalization (Bouchard, Target, Lecours, Fonagy, Tremblay, Schachter, \& Stein, 2008, Fonagy \& Luyten, 2009), symbolization (Klein, 1930/2007), psychological mindedness (Hall, 1992), and metacognition (Dimaggio, Semerari, Carcione, Nicolò, \& Procacci, 2007). In addition, these processes focus on recognizing and processing both one's own mental states and mental states of the partner.

Romantic relationships are thus the very place where two perspectives meet and intersect: the intrapsychic and interpersonal perspective of each of the partners. The intrapsychic, monadic perspective refers to the activation of personal structures and the processing of personal experience. In turn, the interpersonal, dyadic perspective pertains to the activation of intrasubjective representations of the two partners, who-through their behavior in the interaction-mutually influence the intrasubjective worlds of one another and modify it (Bürgin, 2001).

\section{Attachment representations as determinants of satisfaction in relationship}

Within the framework of attachment theory, the basic mental structures that influence relational outcome are the internal working models (Mikulincer, Florian, Cowan, \& Cowan, 2002). At present, authors tend to postulate hierarchical organizations of attachment representations. In the internal representational world, the superior "generalized" attachment models that pertain to expectations toward an attachment figure in general,

\footnotetext{
* Adam Mickiewicz University, Faculty of Social Sciences, Institute of Psychology, Poznań, Poland
} 
co-occur with the context-specific attachment model, which is considered to be an outcome of the current evaluation of the attachment dynamics in a specific relationship (Hazan \& Shaver, 1987, Fraley, Heffernan, Vicary, \& Brumbaugh, 2011, Pierce \& Lydon, 2001). The contents of the internal working model refer to the representation of oneself and of the figure of attachment in an affective relationship, and are described by two dimensions: attachment-related anxiety and avoidance. The anxiety dimension represents the extent to which people tend to worry about the availability and responsiveness of the attachment figure. It reflects a working model of the self as unlovable and endangered by the partner's rejection. The avoidance dimension represents the extent to which people are uncomfortable depending on others and avoid becoming too close in relationships. It reflects a working model of others as unavailable in times of need (Shaver \& Mikulincer, 2002).

Everyday interactions with the partner serve as triggers for affective and behavioral responses that depend upon the attachment representation (Mikulincer \& Shaver, 2003). Attachment anxiety is associated with hyperactivation strategies that serve as a means of maintaining proximity. They surface in the form of excessive demands for reassurance, attention, care, and comfort. Attachment avoidance is associated with deactivation strategies that enable the maintenance of emotional distance from the partner through, for example, suppression of emotions and compulsive self-reliance (Shaver \& Mikulincer, 2007).

These are the types of interactions in which two people, in whom personal attachment representations become activated, meet. At the same time, each of the individuals is a receiver of the partner's behaviors and strategies, which reflect that partner's attachment representations. The intrapsychic perspective here intersects with and permeates the interpersonal perspective. As a result, the relational outcome is determined by the contents of both the actor's and the partner's mental structures, which remain in complex and reciprocal interactions with one another (Mikulincer et al., 2002).

A growing number of studies suggest that attachment style is a significant predictor of relationship satisfaction, both from the point of view of the individual (one's own attachment) and his or her partner (the partner's attachment). Individuals with secure attachment styles state that they are more satisfied with romantic relationships than individuals with avoidant or anxiety style. It has been also shown that relation-specific secure attachment is a predictor of relational satisfaction, whereas global attachment style is not (see Mikulincer et al., 2002 for a review).

The sense of satisfaction due to a relationship has been also investigated from the interpersonal perspective, as being dependent on the partner's attachment representation. Partners of individuals with avoidant attachment styles reported less trust and greater insecurity, whereas partners of individuals with anxiety styles reported less interdependence and less commitment (Simpson, 1990). Moreover, it has been shown that, in unsatisfied couples, women's avoidance is negatively related to men's satisfaction, and men's anxiety is negatively related to women's satisfaction (Mondor, McDuff, Lussier, \& Wright, 2011).

\section{Mentalization as a predictor of satisfaction in relationship}

In interpersonal relationships, apart from the activation of the internal working models and attachment strategies, there also occur processes of inferring the causes of the partner's behavior. The ability to interpret the other person's behaviors in terms of unobservable subjective mental states is a process of social cognition, referred to as mentalization. It incorporates the processes of mental representation and processing, interpretation of mental contents (e.g., beliefs, motives, emotions, intentions, desires, and needs), and making inferences on their basis (Bouchard et al. 2008; Allen, Fonagy, \& Bateman, 2008). The ability to mentalize is acquired in the context of attachment relationships (Fonagy \& Target, 1997) through an interactive, affective regulation and "marked mirroring" (Bateman \& Fonagy, 2004).

The processes of mentalization operate in two directions: towards one's own mental contents and towards the mental contents of the other person (Allen et al., 2008). Mentalization, understood as autoreflection (inferring one's own mental states) is accompanied by mentalization in the interpersonal context (inferring the mental states of other people) (Fonagy, Luyten, Bateman, Gergely, Strathearn, Target, \& Allison, 2010). Accurate mentalization in the interpersonal context means understanding the internal states of other people, regardless of one's personal perspective and engagement in the particular relationship. This depends on the ability to decentralize (Dimaggio, Carcione, Nicolò, Conti, Fiore, Pedone, Popolo, Procacci, $\&$ Semerari, 2009). One of the most important traits of mentalization is its emotion regulation function. Mentalization enables processing emotional experience, transforming primitive and overwhelming affects into more complex, mature, and controllable emotional states (Kernberg, 2011).

All the characteristics of mentalization mentioned above make it a possible predictor of satisfaction in romantic relationships. In close relationships, intrapsychic structures generate emotions and thoughts that are, in fact, a reflection of contents of internal structures, rather than an adequate reaction to relational stimuli. Mentalization is favorable to the more adequate perception of emotional interactions in relationships, to the "realistic understanding" of one's own and other people's mental processes, and to affective and cognitive experiences (Kernberg, 2011, p. 62). Apart from this, mentalization has an influence on emotion regulation, which is considered, in turn, a predictor of satisfaction in romantic relationships (Bloch, Haase, \& Levenson, 2014).

For the satisfaction of couples, mentalization in the interpersonal context seems to be particularly important. However, researchers usually assess people's general 
ability to mentalize and investigate it from the individual perspective. The interpersonal dimension of mentalization has been analyzed in the literature on the subject mainly with reference to the therapeutic relationship (Allen et al., 2008, see also Bucci, 2005; Kernberg, 2011). Moreover, only a small number of authors have investigated mentalization from the theoretical perspective in couples (Josephs \& McLeod, 2014), and only a handful of studies refer to this issue. Notwithstanding the small number of studies, their results emphasize the importance of social cognition processes and of other phenomena related to them for the relational outcome. For example, it has been shown that socioperceptual processes, such as gaze control, can be considered predictors of relationship quality. Specifically, it has been observed that poorer gaze control is associated with an inability to differentiate one's own and the partner's thoughts and emotions, and with a tendency to restrict the partner's autonomy (Petrican, Bielak, Burris, Schimmack, \& Moscovitch, 2011). Moreover, researchers have confirmed the role of mindfulness as a moderator of the relationship between attachment anxiety and relationship stability (Saavedra, Chapman, \& Rogge, 2010). At the same time, there is a shortage of studies dealing with the emotional and unconscious aspects of social cognition, which are particularly important in the context of interactions between partners. The present study addresses this gap, treating mentalization, along with relation-specific attachment, as a significant predictor of relational satisfaction.

\section{Aims and hypotheses}

The purpose of this study was to investigate, from the intrapsychic and interpersonal perspectives, how romantic attachment and mentalization explain relationship satisfaction. The major goal was to determine whether mentalization displays incremental validity in predicting relational satisfaction beyond the effects of contextrelated attachment anxiety and avoidance. First, it was hypothesized that romantic attachment avoidance and anxiety would be negatively associated with relational satisfaction, seen from both the perspective of the actor and of the partner. Second, it was expected that mentalization would display incremental validity over attachment in predicting relational satisfaction, both in the intrapsychic and interpersonal perspective. Moreover, it was predicted that mentalization would be conducive to couple satisfaction.

\section{Participants}

The participants in the study consisted of 32 heterosexual Polish couples between the age of 21 and $38(M=27.36, S D=4.79)$, living in urban areas, who agreed to take part in a study investigating relationships. The sample inclusion criterion was cohabitation for at least two years. The majority of subjects $(68.7 \%)$ had higher education; those with secondary education only constituted $28.1 \%$ of the sample; and $3.2 \%$ had only primary or vocational education. The average duration of the relationships was $M=6.44$ years, $(S D=5.51)$, with $56.3 \%$ of the couples in unformalized relationships.

\section{Methods}

The Mental States Task (MST, Beaulieu-Pelletier, Bouchard, \& Philippe, 2013, adapted by Kwiecień, 2011), based on the Mental States Rating System (Bouchard et al., 2008) is a self-reported method for measuring mentalization. The MST evaluates individual differences in two processes: representation/elaboration and openness/ modulation to one's subjective experience. First, the participants were primed with the 3BM card of the Thematic Apperception Test (Murray, 1971), in order to evoke emotional arousal and regulation strategies. They were then asked to write down a story that came to mind in response to the image. Next, the participants responded to 24 items that assessed their mental states during the previous task. The MST measures the six following mental states, which reflect the interactions between the activation of mental representations and their modulation: Concrete Thinking, Low Defensive Level, Intermediate Defensive Level, Objective-Rational, High Defensive Level, and Reflective Thinking. The score for each subscale reflects the scores for each mental state, and the total MST score is obtained by using an equation that includes weights to reproduce the reflective continuum. The MST has good reliability coefficients $(0.79-0.58$ for the English version and $0.82-0.62$ for the French version).

The Relationship Assessment Scale (RAS, Hendrick, 1988) is a short seven-item questionnaire for assessing relationship satisfaction that can be applied to all types of romantic relationships. The Polish translation of the English version was prepared independently by two psychologists with fluency in English and the most appropriate version was used. Participants answer questions, such as "How much do you love your partner?" on a five-point Likert scale. Higher scores reflect higher relationship satisfaction. The reliability of RAS scores is moderate, with an average of .872 across studies (Graham, Diebels, \& Barnow, 2011).

The Experiences in Close Relationships-Relationship Structures (ECR-RS, Fraley et al., 2011, adapted by Marszał, 2015) has been designed to examine attachment in different relationship contexts (mother, father, romantic partner, friend). Nine items are used to assess attachment anxiety and avoiding in each domain. Items were assessed on a 7-point scale, ranging from 1 (strongly disagree) to 7 (strongly agree). Six items in each domain refer to the level of anxiety, while three items in each domain refer to the level of avoiding. The reliability of the tool, depending on the specific attachment relation, ranges from a Cronbach's $\alpha$ of 0.85 to 0.91 (Fraley et al., 2011). In the present report, only items referring to the specific attachment to the partner were taken into account. The reliability of the Polish version of the attachment dimensions in the context of a relationship with a partner has a Cronbach's $\alpha=.877$ for attachment anxiety and $\alpha=.842$ for attachment avoidance (Marszał, 2015). 


\section{Results}

The descriptive data, paired $t$-tests, and correlations between the variables are presented in Table 1. The relations between age and duration of relationship and the relational outcome were also examined. Neither the age of participants nor the duration of the relationship correlated significantly with the relational satisfaction (all values of $p>0.05)$.

To test whether the attachment dimensions (anxiety and avoidance) and mentalization predict relational satisfaction, four hierarchical regression analyses were conducted. The attachment dimensions were inserted simultaneously in step 1 , and mentalization was added to step 2 . In order to examine the actor's effect on his or her own relational satisfaction, the respondent's attachment anxiety and avoidance were entered in step 1. To examine the partner's effect on the respondent's relational satisfaction, the partner's attachment dimensions were inserted in step 1 .

Taking into consideration the actor's perspective, significant negative effects of attachment anxiety and avoidance on relational satisfaction were found for both men and women. In women, the attachment dimensions together explained $44 \%$ of the relational satisfaction variance $F(2,29)=13.2 ; p<.001$. In men, attachment anxiety and avoidance together explained $56 \%$ of the relational satisfaction variance $F(2,29)=20.58 ; p<.001$. Mentalization did not show incremental validity when entered in the second step (Table 2).

Regarding the partner's perspective, the significant negative effect of the partner's attachment anxiety on the individual's relational satisfaction was observed for both men and women. The partner's attachment avoidance did not contribute significantly to the explanation of the individual's relational satisfaction. In women, mentalization showed incremental validity when added to the second step. When mentalization was added to the regression model, the $\mathrm{R}^{2}$ change was .13 $(\mathrm{p}<.001)$. This overall model accounted for $63 \%$ of the relation satisfaction variance, $F(3,28)=18.26, p<.001$. Mentalization thus exhibited incremental validity over and above the partner's attachment dimensions. In men, mentalization did not show incremental validity when added to the second step (Table 3).

Table 1. Means, SD, paired t-tests, and correlations between variables

\begin{tabular}{|c|c|c|c|c|c|c|c|c|c|c|c|}
\hline & 1. & 2. & 3. & 4. & 5. & 6. & 7. & $M(S D)$ men & $M(S D)$ women & $t$ paired & $p$ \\
\hline 1. Anxiety W & & & & & & & & & $2.30(1.73)$ & \multirow{2}{*}{-.58} & \multirow{2}{*}{ ns } \\
\hline 2. Anxiety $M$ & $.45^{* *}$ & & & & & & & $2.14(1.21)$ & & & \\
\hline 3. Avoidance W & $.42^{*}$ & $.40^{*}$ & & & & & & & $1.92(1.16)$ & \multirow{2}{*}{.61} & \multirow{2}{*}{ ns } \\
\hline 4. Avoidance M & .33 & $.49^{*}$ & $.37^{*}$ & & & & & $2.06(1.06)$ & & & \\
\hline 5. Mentalization W & -.30 & .06 & -.08 & .16 & & & & & $1.95(0.17)$ & \multirow{2}{*}{.44} & \multirow{2}{*}{ ns } \\
\hline 6. Mentalization M & -.02 & .25 & -.01 & -.02 & .003 & & & $1.88(0.19)$ & & & \\
\hline 7. Satisfaction W & $-.59^{* *}$ & $-.72^{* *}$ & $-.57^{* *}$ & -.25 & .32 & -.17 & & & $4.21(0.68)$ & \multirow{2}{*}{-1.49} & \multirow{2}{*}{ ns } \\
\hline 8. Satisfaction M & $-.48^{* *}$ & $-.65^{* *}$ & $-.36^{*}$ & $-.65^{* *}$ & -.06 & -.16 & $.52^{* *}$ & $4.26(0.59)$ & & & \\
\hline
\end{tabular}

Note: $\mathrm{W}=$ Women; $\mathrm{M}=$ Men

${ }^{*} p<0.05 ;{ }^{* *} p<0.01$

Table 2. Summary of hierarchical regression analysis for attachment avoidance, attachment anxiety, and mentalization as predictors of relational satisfaction-actor's perspective

\begin{tabular}{|c|c|c|c|c|c|c|c|c|}
\hline & \multicolumn{4}{|c|}{ women } & \multicolumn{4}{|c|}{ men } \\
\hline & $B(S E B)$ & $\beta$ & $R^{2}$ & $\Delta R^{2}$ & $B(S E B)$ & $\beta$ & $R^{2}$ & $\Delta R^{2}$ \\
\hline step 1 & & & .48 & & & & .59 & \\
\hline Actor Anxiety & $-.17(.06)$ & $-.42^{* *}$ & & & $-.25(.08)$ & $-.46^{* *}$ & & \\
\hline Actor Avoidance & $-.23(.09)$ & $-.40^{*}$ & & & $-.21(.07)$ & $-.43^{* *}$ & & \\
\hline step 2 & & & .50 & .03 & & & .59 & 0.003 \\
\hline Mentalization & $.72(.55)$ & .18 & & & $-.19(.39)$ & -.06 & & \\
\hline
\end{tabular}


Table 3. Summary of hierarchical regression analysis for attachment avoidance, attachment anxiety, and mentalization as predictors of relational satisfaction-partner's perspective

\begin{tabular}{|c|c|c|c|c|c|c|c|c|}
\hline & \multicolumn{4}{|c|}{ women } & \multicolumn{4}{|c|}{ men } \\
\hline & $B(S E B)$ & $\beta$ & $R^{2}$ & $\Delta R^{2}$ & $B(S E B)$ & $\beta$ & $R^{2}$ & $\Delta R^{2}$ \\
\hline step 1 & & & .54 & & & & .26 & \\
\hline Partner Anxiety & $-.44(.08)$ & $-.77^{* *}$ & & & $-.14(.06)$ & $-.40^{* *}$ & & \\
\hline Partner Avoidance & $.06(.09)$ & .10 & & & $-.10(.09)$ & -.20 & & \\
\hline step 2 & & & .66 & $13^{* *}$ & & & .29 & .03 \\
\hline Mentalization & $1.42(.44)$ & $.40^{* *}$ & & & $-.54(.49)$ & & & \\
\hline
\end{tabular}

\section{Discussion}

The aim of the present study was to determine whether context-specific attachment and mentalization can be considered predictors of satisfaction in a relationship. There already exists much data indicating that there is a relationship between attachment anxiety and avoidance and relational satisfaction. At the same time, mentalization - due to its interpersonal aspect and emotion regulation function-becomes a potential predictor of relationship outcome. For this reason, the main aim of the study was to verify whether mentalization displays incremental validity in predicting relational satisfaction beyond attachment anxiety and avoidance.

The attachment hypothesis was tested from both the intrapsychic and interpersonal perspectives. The author checked whether the actor's own dimensions of attachment, and the respective dimensions of the partner, can be considered predictors of relational satisfaction. In the actor's perspective, relationships between the two dimensions of attachment and relational satisfaction have been observed. In the case of both women and men, higher levels of attachment anxiety and avoidance turned out to be predictors of a lower level of satisfaction in relationship. The obtained results remain in accord with the results of previous research (e.g., Naud, Lussier, Sabourin, Normandin, Clarkin, \& Kernberg, 2013; Saavedra et al., 2010) and fit into the whole collection of studies confirming the importance of internal representations to present interpersonal relations.

From the perspective of the partner, whether in the case of women or men, attachment anxiety also proved to be a predictor of the relationship outcome. At the same time, no relationship between relationship satisfaction and the attachment avoidance of women and men was observed. A thorough analysis of the dependencies between the attachment dimensions and the relational outcome reveals the existence of stronger relationships with attachment anxiety (see e.g., Mondor et al., 2011). The anxiety activation of internal representations is accompanied by the emergence of hyperactivation strategies, which aim at increasing closeness and regulating anxiety. The use of such strategies, such as compulsive demands for support, causes conflicts in the sphere of autonomy and dependency between the partners (Joraschky \& Petrowski, 2008, following Nolte, Guiney, Fonagy, Mayes, \& Luyten, 2011). Moreover, behaviors of individuals with attachment anxiety cause a sense of guilt in their partners, which decreases their sense of satisfaction in relationship (Overall, Girme, Lemay and Hammond, 2014). In turn, deactivation strategies characteristic of attachment avoidance, including emotional cutoff (Wei, Vogel, Ku, \& Zakalik, 2005), serve to increase distance from the other. This is the way such individuals avoid potential conflicts and rejection by other people (see Shaver \& Mikulincer, 2002). Although in the long run, using this strategy pushes others away, exposes the person to loneliness, and is associated with considerable personal costs, temporary deactivation can be a protective strategy (see: Wei et al., 2005). This is why partners may consider deactivation strategies as far less threatening than hyperactivation strategies. As a consequence, deactivation strategies may not be a factor that determines the partners' relational satisfaction.

The main aim of this study was to determine whether mentalization shows incremental validity in predicting relational satisfaction beyond the attachment dimensions. This hypothesis was confirmed in the case of the attachment dimensions of women's partners. The attachment anxiety of men and women's ability to mentalize together explain $63 \%$ of women's relational satisfaction variance. The relationship between the man's attachment anxiety and the woman's satisfaction is negative, whereas the relationship between the woman's ability to mentalize and her relational satisfaction is positive. These results suggest that a higher level of mentalization in women is associated with higher satisfaction for them in relationships, despite their partner's attachment anxiety. The mechanism for this phenomenon is probably associated with the ability to decentralize (Dimaggio et al., 2009), which is characteristic of good mentalization, and the emotion 
regulation function of mentalization (Kernberg, 2011). Moreover, there are some tentative data that suggest that inferring the mental states of others is associated with accuracy in recognizing emotional cues (e.g., Turner, Wittkowski, \& Hare, 2008), which corresponds with Kernberg's assumption that mentalization is favorable to a more adequate perception of emotional interactions in relationships (2011). Thanks to the ability to recognize the partner's emotional states irrespective of her own perspective, the woman can interpret the man's hyperactive strategies as not threatening (as not restricting autonomy) and as not overly demanding, but rather as resulting from his sense of threat. In other words, through mentalization, a more adequate perception of the sources and meanings of behaviors resulting from the man's attachment anxiety is possible. It seems that such an interpretation enables women to regulate their emotions - for example, it diminishes their sense of guilt associated with hyperactivation strategies manifested by their partners; this is, in turn, conducive to women's higher satisfaction with their romantic relationships (see Bloch et al., 2013).

The incremental validity of mentalization as a predictor of relational satisfaction alongside the partner's attachment dimensions was observed exclusively in the case of women. The men's satisfaction in romantic relationships did not depend on their ability to understand the mental states of their partners. This result poses questions about the role of sex-related differences in mentalization. The results of studies in this sphere are equivocal; some indicate a lack of differences between women and men (Overall et al., 2014), while some reveal sex differences in the mentalization dimensions - for example, in mentalized affectivity (it has been observed that women show a higher level of internalization, whereas men manifest a higher level of externalization; Lecours, Sanlian, \& Bouchard, 2007). In the present study, the overall result of mentalization did not differentiate between men and women; therefore, no difference that could explain the lack of incremental validity of mentalization in predicting relational satisfaction in men was found. Some authors suggest that women are more socially motivated to employ this ability (Rutherford, Wareham, Mayes, Vrouva, Fonagy, \& Potenza, 2012), and that mentalization can thus play a crucial role in their interpersonal relationships. It is also significant that mentalization is the predictor of satisfaction in relationships alongside the partner's attachment anxiety (though not avoidance). Women are socialized in such a way as to be more relation-oriented and emotionoriented, which is more characteristic of attachment anxiety. Due to this, they can probably better understand, tolerate, and perceive as nonthreatening the hyperactive strategies of their partners.

Although the incremental validity of mentalization was observed in the female participants when the partner's perspective had been taken into consideration, it turned out to be insignificant for relational satisfaction from the perspective of the actor, in the case of both women and men. There are two possible explanations of this result. The first is associated with the research procedure itself, which involved the participants, in the first step, producing a story about a person in the picture presented to them, and in the second step, in describing their own thoughts and feelings in the course of formulating the story (Beaulieu-Pelletier, et al., 2013). This procedure reflected the interpersonal dynamics of mentalizationfirst focusing on the emotional states of another person, and then reflecting on one's own mental states activated in the context of the other person. This procedure design makes it difficult to separately capture the personal perspective (recognition and elaboration of one's own intrapsychic states) and the perspective of another person (recognition and elaboration of someone else's intrapsychic states). Perhaps applying methods based on the assumption of the modularity of mentalization processes (see Carcione, Dimaggio, Conti, Fiore, Nicolò, \& Semerari, 2010) would enable the identification of the independent input of the intrapsychic and interpersonal aspects of mentalization in the explanation of relational satisfaction. The second possible explanation for the result would be to accept an assumption that, for relational satisfaction, in fact, only mentalization in the context of the partner's attachment is important, and not in the context of one's own attachment. Although such an assumption should be treated with a great deal of caution, at least for the time being, it raises further questions about, for example, the differences in processing one's own and someone else's experiences. Future studies should, therefore, strive to take into account the difficulties associated with the complex and complicated nature of mentalization itself, intensified even by the application of the intrapsychic and interpersonal perspective (Bürgin, 2001, Mikulincer et al., 2002).

The present study constitutes a clear contribution to the understanding of the predictors of relational satisfaction, but it is not free from limitations. The most serious limitation pertains to the size of the research sample, which seems insufficient to investigate the effect of the actor and the partner jointly, with the use of actorpartner interdependence modeling (Kenny \& Cook, 1999). In interpreting the results of the present study, it needs to be borne in mind that the perspective of the actor and the partner have been treated separately here, which might have led to overlooking the dual effect of the actor's and the partner's attachment on satisfaction in relationship. Future studies should be, therefore, conducted on larger samples, in order to be able to test the hypotheses regarding the intrapsychic and interpersonal perspectives jointly. At the same time, it seems desirable to apply methods that can examine different dimensions of mentalization, both focused on one's own mental states and the mental states of other people. 


\section{References}

Allen, J.G., Fonagy, \& P., Bateman, A. (2008). Mentalizing in Clinical Practice. Washington, DC: American Psychiatric Publishing Inc.

Bateman, A., \& Fonagy, P. (2004). Psychotherapy for borderline personality disorder: Mentalization-based treatment. Oxford, England: Oxford University Press.

Beaulieu-Pelletier, G., Bouchard, M.-A., \& Philippe, F.L. (2013) Mental States Task (MST): Development, Validation, and Correlates of a Self-Report Measure of Mentalization: Mental States Task. Journal of Clinical Psychology, 69, 671-695. doi: $10.1002 /$ jclp. 21942

Bloch, L., Haase, C.M., \& Levenson, R.L. (2013). Emotion Regulation Predicts Marital Satisfaction: More Than a Wives' Tale. Emotion, 14, 130-144. doi: 10.1037/a0034272

Bowlby, J. (1973). Attachment and Loss: Separation: anxiety and anger. New York: Basic Books.

Bouchard, M.-A., Target, M., Lecours, S., Fonagy, P., Tremblay, L.-M., Schachter, A., \& Stein, H. (2008). Mentalization in adult attachment narratives: Reflective functioning, mental states, and affect elaboration compared. Psychoanalytic Psychology, 25, 47-66. doi 10.1037/0736-9735.25.1.47

Bradbury, T.N., Fincham, F.D., \& Beach, S.R.H. (2000). Research on the nature and determinants of marital satisfaction: A decade in review. Journal of Marriage and the Family, 62, 964-980. doi: 10.1111/j.1741-3737.2000.00964.x

Bucci, W. (2005). The Interplay of subsymbolic and symbolic processes in psychoanalytic treatment. Psychoanalytic Dialogue, 15, 855-873. doi: 10.1080/10481885.2011.545326

Bürgin, D. (2011). From outside to inside to outside: comments on intrapsychic representations and interpersonal interactions. Infant Mental Health Journal, 32, 95-114. doi: 10.1002/imhj.20285

Carcione, A., Dimaggio, G., Conti, L., Fiore, D., Nicolò, G., \& Semerari, A. (2010). Metacognition Assessment Scale v. 4.0 [unpublished manuscript]

Dimaggio, G., Carcione, A., Nicolò, G., Conti, L., Fiore, D., Pedone, R., Popolo, R., Procacci, M., \& Semerari, A. (2009). Impaired Decentration in Personality Disorder: A Series of Single Cases Analysed with the Metacognition Assessment Scale. Clinical Psychology and Psychotherapy, 16, 450-462. doi: 10.1002/cpp.619

Dimaggio, G., Semerari, A., Carcione, A., Nicolò, G., \& Procacci, M. (2007). Psychotherapy of personality disorder: Metacognition, states of mind and interpersonal cycles. London: Routledge.

Fonagy, P., \& Target, M. (1997). Attachment and reflective function: Their role in self-organization. Development and Psychopathology, 9, 679-700. doi: 10.1017/S0954579497001399

Fonagy, P., \& Luyten, P. (2009). A developmental, mentalization-based approach to the understanding and treatment of borderline personality disorder. Development and Psychopathology, 21, 1355-1381. doi:10.1017/S0954579409990198

Fonagy, P., Luyten, P., Bateman, A.W., Gergely, G., Strathearn, L., Target, M., \& Allison, E. (2010). Attachment and personality pathology. In J. Clarkin, P. Fonagy, G. Gabbard (Eds.), Psychodynamic Psychotherapy for Personality Disorders: A Clinical Handbook. (pp. 37-88) Arlington, VA: American Psychiatric Publishing, Inc.

Fraley, R.C., Heffernan, M.E., Vicary, A.M., \& Brumbaugh, C.C. (2011) The Experiences in Close Relationships-Relationship Structures questionnaire: a method for assessing attachment orientations across relationships. Psychological Assessment, 23, 615-625. doi: $10.1037 / \mathrm{a} 0022898$

Graham, J.M., Diebels, K.J., \& Barnow, Z.B. (2011). The Reliability of Relationship Satisfaction: A Reliability Generalization MetaAnalysis. Journal of Family Psychology, 25, 39-48. doi: 10.1037 a0022441

Hall, J.A. (1992). Psychological-mindedness: a conceptual model. American Journal of Psychotherapy, 46, 131-140.

Hazan, C., \& Shaver, P. (1987). Romantic love conceptualized as an attachment process. Journal of Personality and Social Psychology, 52, 511-524. doi: http://dx.doi.org/10.1037/0022-3514.52.3.511

Hendrick, S.S. (1988). A generic measure of relationship satisfaction. Journal of Marriage and the Family, 50, 93-98. doi: 10.2307/352430
Joraschky, P., \& Petrowski, K. (2008). Angst und Bindung. In B. Strauß (Ed.), Bindung und Psychopathologie (pp. 49-80). Stuttgart: KlettCotta.

Josephs, L., \& McLeod, B.A. (2014). A theory of mind-focused approach to anger management. Psychoanalytic Psychology, 31, 68-83. doi: $10.1037 / \mathrm{a} 0034175$

Kenny, D.A., \& Cook, W. (1999). Partner effects in relationship research: Conceptual issues, analytic difficulties, and illustrations. Personal Relationships, 6, 433-448. doi: 10.1111/j.1475-6811.1999. tb00202.x

Kernberg, O.F. (2011). Mentalization, Insight, Empathy, and Interpretation. In O.F. Kernberg, (Ed.), The Inseparable Nature of Love and $A g$ gression. Clinical and Theoretical Perspectives (pp. 57-79). Washington, DC London, England: American Psychiatric Publishing.

Kernberg, O.F., \& Caligor, E. (2005). A Psychoanalytic Theory of Personality Disorders. In J.F. Clarkin \& M.F. Lenzenweger, (Eds.), Major theories of personality disorder (pp. 114-156). New York, NY: Guilford Press.

Klein, M. (1930/2007). Znaczenie tworzenia symboli w tworzeniu ego (The importance of Symbol-Formation in the development of the Ego). In M. Klein (Ed.), Miłość, poczucie winy i reparacja (pp. 217-230). Gdańsk: GWP

Kwiecień, A. (2011). Aktywowanie wewnętrznych reprezentacji przywiqzania a mentalizacja u osób o strukturze osobowości borderline (Mentalization under activating internal attachment representation's in borderline personality organization). Unpublished master's dissertation, Adam Mickiewicz University, Poznań.

Lecours, S., Sanlian, N., \& Bouchard, M.-A. (2007). Assessing verbal elaboration of affect in clinical interviews: Exploring sex differences. Bulletin of the Menninger Clinic, 71, 227-247.

Marszał, M. (2015). Mentalizacja w kontekście przywiazania. Zdolnośc do rozumienia siebie $i$ innych u osób $z$ osobowościa borderline (Mentalization in the context of attachment. The ability to understand self and others in borderline pathology). Warszawa: Difin.

Mikulincer, M., Florian, V., Cowan, P.A., \& Cowan, C.P. (2002). Attachment security in couple relationships: A systemic model and its implications for family dynamics. Family Processes, 41, 405-432. doi: $10.1111 / j .1545-5300.2002 .41309 . x$

Mikulincer, M., \& Shaver, P.R. (2003). The attachment behavioral system in adulthood: Activation, psychodynamics, and interpersonal processes. In M.P. Zanna (Ed.), Advances in experimental social psychology (Vol. 35, pp. 53-152). San Diego, CA, US: Elsevier Academic Press.

Mondor, J., McDuff, P., Lussier, Y., \& Wright, J. (2011). Couples in Therapy: Actor-Partner Analyses of the Relationships Between Adult Romantic Attachment and Marital Satisfaction. The American Journal of Family Therapy, 39, 112-123. doi: 10.1080/01926187.2010.530163

Murray, H.A. (1971). Thematic Apperception Test: Manual. Cambridge: Harvard University Press.

Naud, C., Lussier, Y., Sabourin, S., Normandin, L., Clarkin, J.F., \& Kernberg, O.F. (2013). How Attachment and Excessive Self-Sacrificing Depressive Dynamics Are Related to Couple Relationship Satisfaction Over Time. Couple and Family Psychology: Research and Practice, 2, 14-33. doi: 10.1037/a0031705

Nolte, T., Guiney, J., Fonagy, P., Mayes, L.C., \& Luyten, P. (2011). Interpersonal stress regulation and the development of anxiety disorders: an attachment-based developmental framework. Frontiers in Behavioral Neuroscience, 5, 1-21. doi: 10.3389/fnbeh.2011.00055

Overall, N.C., Girme, Y.U., Lemay, \& E.P., Hammond, M.D. (2014). Attachment Anxiety and Reactions to Relationship Threat: The Benefits and Costs of Inducing Guilt in Romantic Partners. Journal of Personality and Social Psychology, 106, 235-256. doi: 10.1037/ a0034371

Petrican, R., Bielak, T., Burris, C. T., Schimmack, U., \& Moscovitch, M. (2011). For My Eyes Only: Gaze Control, Enmeshment, and Relationship Quality. Journal of Personality and Social Psychology, 100, 1111-1123. doi: 10.1037/a0021714

Pierce, T., \& Lydon, J. (1998). Priming relational schemas: Effects of contextually activated and chronically accessible interpersonal 
expectations on responses to a stressful event. Journal of Personality and Social Psychology, 75, 1441-1448. doi: 10.1037/00223514.75.6.1441

Rutherford, H.J.V., Wareham, J.D., Mayes, L.C., Vrouva, I., Fonagy, P., \& Potenza, M.N.,(2012). Sex Differences Moderate the Relationship Between Adolescent Language and Mentalization. Personality Disorders: Theory, Research, and Treatment, 3, 393-405. doi: 10.1037/ a0028938.

Saavedra, M.C., Chapman, K.E., \& Rogge, R.D. (2010). Clarifying Links Between Attachment and Relationship Quality: Hostile Conflict and Mindfulness as Moderators. Journal of Family Psychology, 24 380-390. doi: 10.1037/a0019872

Shaver, P.R., \& Mikulincer, M. (2002). Attachment-related psychodynamics. Attachment \& Human Development, 4, 133-161. doi: 10.1080/1461673021015417 1
Shaver, P.R., Mikulincer, M. (2007). Adult attachment strategies and the regulation of emotion. In J.J. Gross (Ed.), Handbook of emotion regulation (pp. 446-465). New York: Guilford Press.

Simpson, J.A. (1990). Influence of Attachment Styles on Romantic Relationships. Journal of Personality and Social Psychology, 59, $971-$ 980. doi: 10.1037/0022-3514.59.5.971

Turner, J.M., Wittkowski, A., \& Hare, D.J. (2008). The relationship of maternal mentalization and executive functioning to maternal recognition of infant cues and bonding. British Journal of Psychology, 99, 499-512. doi: 10.1348/000712608X289971

Wei, M., Vogel, D.L., Ku, T., \& Zakalik, R.A. (2005). Adult Attachment, Affect Regulation, Negative Mood, and Interpersonal Problems: The Mediating Roles of Emotional Reactivity and Emotional Cutoff. Journal of Counseling Psychology, 52, 14-24. doi: 10.1037/0022-0167.52.1.14 